Volume 9, No.5, September - October 2020

International Journal of Advanced Trends in Computer Science and Engineering

Available Online at http://www.warse.org/IJATCSE/static/pdf/file/ijatcse316952020.pdf

https://doi.org/10.30534/ijatcse/2020/316952020

\title{
An eLearning Solution based on Cloud in Response to the COVID-19 Pandemic in Vietnam
}

\author{
Vu Khanh Quy, Pham Minh Chuan, Vu Xuan Thang, Vi Hoai Nam, Nguyen Thi Thanh Hue, \\ Pham Quoc Hung \\ Hung Yen University of Technology and Education, Hungyen, Vietnam \\ quyvk@utehy.edu.vn, chuanpm@utehy.edu.vn, xuanthangutehy@gmail.com, vihoainam@utehy.edu.vn, \\ huentt1509@gmail.com, quochungvnu@gmail.com
}

\begin{abstract}
In While Asians were still thrilled to welcome the traditional Lunar New Year holiday, the Coronavirus outbreak began in Wuhan, China, and just a few days later, it quickly became a worldwide epidemic. According to WHO statistics, as of March 07, 2020, over 10,000 people worldwide have died from the disease. The danger of Coronavirus is that it can be spread directly from person to person with just a handshake or close contact. Schools are the first places to be affected by the Corona epidemic due to the number of large students who can increase the risk of transmission. Therefore, the ban on large group gatherings has been issued by many countries. A lot of schools in many countries have to close until further announcement from the Government, including Vietnam. However, learning can't be interrupted, more than 27 million Vietnamese students, and hundreds of millions of worldwide students need to continue learning. Urgent online training solutions have been deploying. In this study, we provide a solution that has been implemented at the Hung Yen University of Technology and Education. The initial evaluation results show that our solution is very feasible when implemented in emergencies to cope with unexpected epidemics and for schools in middle and low-income countries.
\end{abstract}

Key words: e-Learning, COVID-19, Coronavirus, Solution, Vietnam.

\section{INTRODUCTION}

In the first days of the new year 2020, when Asian countries were still in the Lunar New Year holidays, the first information about the outbreak of the COVID-19 (also known as Coronavirus or Wuhanvirus) in China began spreading on the Internet. The first research results show that the Coronavirus has its full scientific name as $\mathrm{n}-\mathrm{CoV}-2$ (or SARS-CoV-2), which is related to the SAR Virus, which caused the SARS 2003 pandemic and killed more than 7,000 people worldwide. Coronavirus outbreak has been determined to begin from a seafood market in Wuhan City, China. Shortly thereafter, this epidemic began spreading in many Chinese cities, then to neighbouring countries in Asia, Europe, and became a worldwide pandemic [1].

Studies also indicate a dangerous characteristic of
Coronavirus, different from other viruses. If other viruses are not able to be transmitted directly from person to person (the bat is host transmits SAR), Coronavirus can be transmitted directly from person to person through breathing. A person who is infected with Corona when sneezing can spread it to people within a radius of about $2 \mathrm{~m}$. The Coronavirus can also survive airborne for several hours, even up to 24 hours under certain conditions. Another dangerous feature is that the Coronavirus is capable of being transmitted even if infected people do not yet have any symptoms (symptoms such as cough, fever, shortness of breath). A person infected with the virus can incubate the disease for 4-7 days before developing symptoms of illness.

During this time, this person will be a source of mobile disease to the community without even knowing he or she is ill. A third dangerous characteristic is that the Coronavirus can enter and damage the lungs, which can be lethal [2]. To limit the spread, the Chinese Government on January 23, 2020, had to declare a state of emergency and quarantine the entire city of Wuhan with over 11 million people. Hours later, Hoang Cuong with 6 million people and then Ngac-Chau with over 3 million people were also blockaded. The total people number blockaded in the three cities is about over 20 million $[3,18]$.

Table 1. Top countries are most affected by Coronavirus.

\begin{tabular}{|c|c|c|c|c|c|}
\hline $\begin{array}{c}\text { Orde } \\
\mathbf{r}\end{array}$ & Country & $\begin{array}{l}\text { Total } \\
\text { Cases }\end{array}$ & $\begin{array}{c}\text { Total } \\
\text { Deaths }\end{array}$ & $\begin{array}{c}\text { Total } \\
\text { Recovered }\end{array}$ & $\begin{array}{l}\text { Active } \\
\text { Cases }\end{array}$ \\
\hline 1 & China & 81.285 & 3.287 & 74.051 & 3.947 \\
\hline 2 & Italy & 74.386 & 7.503 & 9.362 & 57.521 \\
\hline 3 & USA & 68.489 & 1.032 & 394 & 67.063 \\
\hline 4 & Spain & 49.515 & 3.647 & 5,367 & 40.501 \\
\hline 5 & Germany & 37.323 & 206 & 3,547 & 33.570 \\
\hline 6 & Iran & 27.017 & 2.077 & 9,625 & 15.315 \\
\hline 7 & France & 25.233 & 1.331 & 3,900 & 20.002 \\
\hline 8 & $\begin{array}{c}\text { Switzerlan } \\
d\end{array}$ & 10.897 & 153 & 131 & 10.613 \\
\hline 9 & UK & 9.529 & 465 & 135 & 8.929 \\
\hline 10 & S. Korea & 9.241 & 131 & 4,144 & 4.966 \\
\hline \multicolumn{2}{|c|}{ Statistics } & 392.915 & 19.832 & 110.656 & 262.427 \\
\hline
\end{tabular}


Despite many robust solutions, the outbreak of Coronavirus is inevitable. First are neighbouring countries, then many other countries in Asia, Europe, Australia, and the United States [19]. Among them, South Korea [23] and Italy [24] currently are the black spots of disease outbreaks, Table 1. According to Washington Post [4], on March 10, 2020, the Italian Government had to issue an order to isolate the entire population, more than 60 million people banned from the road (except to buy necessities), all public activities, crowded gatherings are forced to cancel. Before that, in South Korea, people were encouraged to avoid the streets and crowded places, a series of countries closed schools and asked students to stay home, according to The Guardian [5].

In Vietnam, the authorities have been very proactive, fiercely preventing the Coronavirus epidemic as soon as it started to appear in China. However, with over $1.000 \mathrm{~km}$ of the border and the convenient movement between two countries, the entry of the Coronavirus into Vietnam is unavoidable [6]. On January 22, 2020, the first case of Coronavirus has discovered was a father and son from Wuhan, China, who travelled to Vietnam on vacation [7]. Since then, on March 23, 2020, Vietnam has recorded over 120 cases of Coronavirus infection, mainly patients entered Vietnam from China, Japan, England and Korea.

According to the annual plan, Table 2, all over 5 million Vietnamese students will return to the school after the 7-day Lunar New Year holiday, from January 23, 2020, to January 29,2020 . On January 30, 2020, just one day after all students went to school, realizing that the situation of infection could be complicated when students returned to school, the Government noticed to all students leave school. Since then, it has been over two months. Students in Vietnam and many countries around the world still have to stay at home. To cope with the increasing and complicated spread of Coronavirus disease, many solutions such as e-learning and combined learning have been implemented. Accordingly, some top universities have e-Learning Management Systems (LMS), which are invested much money and used for a long time. Most other schools do not yet have this system while the implementation time is calculated in days and very urgent. In this article, we focus on introducing some low cost, effective E-learning solutions, which can be implemented quickly and efficiently to cope with pandemic (such as the current Coronavirus). Moreover, the survey results of over 1.000 students who have participated in our online classes conducted at Hung Yen University of Technology and Education in Vietnam show that students are more excited, active and more proactive when participating courses. The actual implementation shows that our solution is suitable for schools in middle and low-income countries, that are not yet equipped with modern LMS systems but need to organize training online activities to cope with epidemics in an emergency.

\section{TEACHING-LEARNING ISSUES IN EPIDEMIC DISASTERS}

When an epidemic occurs, economic activities, services and tourism in a region or city may be delayed or stopped.
However, the training problem has its own unique[22]. Usually, each country has about $30 \%$ school-age population. In Vietnam, every day, about $30 \%$ of the population (about 27 million people) go to school, especially, pupils and students can come from many different provinces and cities (possibly from epidemic areas). Only one person infected with Coronavirus in school, the possibility of that person infecting people in his or her community is very high.

Recognizing this risk, the Vietnamese Government has suspended all schools. All students are absented from school for more than two months since the 2020 Lunar New Year (the begin of the I semester to the middle of the II semester of the academic year 2019-2020). However, the suspension of school cannot last forever while the disease situation is getting more and more complicated, and students, pupils cannot go to school yet. Some of the top universities have been equipped with LMS for training online. However, most other schools do not yet have this system due to funding problems. In low- and middle-income countries, investing in a modern and professional LMS system is a challenging problem and requires investment from the Government.

As analyzed above, the schools in Vietnam in general and the Hung Yen University of Technology and Education (UTEHY) [12] in particular, have been affected seriously by the Coronavirus pandemic. The UTEHY is under the Ministry of Education and Training in Vietnam. It has three campuses. Head-office is over 15ha, training about 6,000 students at Khoai Chau District, Hung Yen Province. It is $40 \mathrm{~km}$ far from Hanoi. Campus 2 is 28ha, training about 3,000 students, in My-Hao District, Hung Yen Province, It is $32 \mathrm{~km}$ far from Hanoi, and Campus 3 is 1.5 ha in Hai Duong City, it is $70 \mathrm{~km}$ far from Hanoi. The total number of students currently in training is over 9,000 students from undergraduate to the doctorate level with over 500 existing lecturers. Table 2 shows the UTEHY' training plan, the academic year 2019-2020.

Table 2. The academic year 2019-2020 at the UTEHY.

\begin{tabular}{|c|c|c|c|}
\hline $\begin{array}{l}\text { Calendar } \\
\text { (month) }\end{array}$ & Semester (S) & Main activities & Seismic event \\
\hline $7-8$ & Summer 2019 & Minimal teaching & \\
\hline 9 & S1 & Lectures start & \\
\hline 10 & S1 & $\begin{array}{l}\text { Opening, new student } \\
\text { enrollment }\end{array}$ & \\
\hline 11 & S1 & $\begin{array}{l}\text { Lectures, } \\
\text { Mid-semester exams }\end{array}$ & \\
\hline 12 & S1 & $\begin{array}{l}\text { Lectures end, } \\
\text { Final semester exams }\end{array}$ & \\
\hline 1 & Sart S2, 2020 & Lectures start & \\
\hline 2 & S2 & Lunar New Year & \multirow{3}{*}{$\begin{array}{l}\text { Due tothe } \\
\text { COVID-19, all } \\
\text { schools in } \\
\text { Vietnam are } \\
\text { closed. }\end{array}$} \\
\hline 3 & S2 & Lectures resume & \\
\hline 4 & S2 & $\begin{array}{l}\text { Lectures, } \\
\text { Mid-semester exams }\end{array}$ & \\
\hline 5 & S2 & $\begin{array}{l}\text { Lectures end, end of } \\
\text { year exams start }\end{array}$ & \multirow{2}{*}{$\begin{array}{l}\text { Studies that } \\
\text { predict the } \\
\text { disease will } \\
\text { continue. }\end{array}$} \\
\hline 6 & $\mathrm{~S} 2$ & $\begin{array}{l}\text { Lectures end, Final } \\
\text { semester exams. }\end{array}$ & \\
\hline
\end{tabular}

Source: The UTEHY' training program, 2019-2020. 
Like other universities in Vietnam, after the COVID-19 epidemic broke out, UTEHY gave students two weeks off (extending the Tet holiday to 4 weeks). Entire schools are not allowed to concentrate training due to the epidemic situation. However, the suspension of training cannot continue; the school board decided to organize online training for over 9.000 students in this emergency condition. Like many other schools, the first time UTEHY implemented online training to all students, it encountered many difficulties and challenges in facilities, people, equipment, internet connection and especially in selecting a solution to support online training (Fig.1 and, Fig. 2).

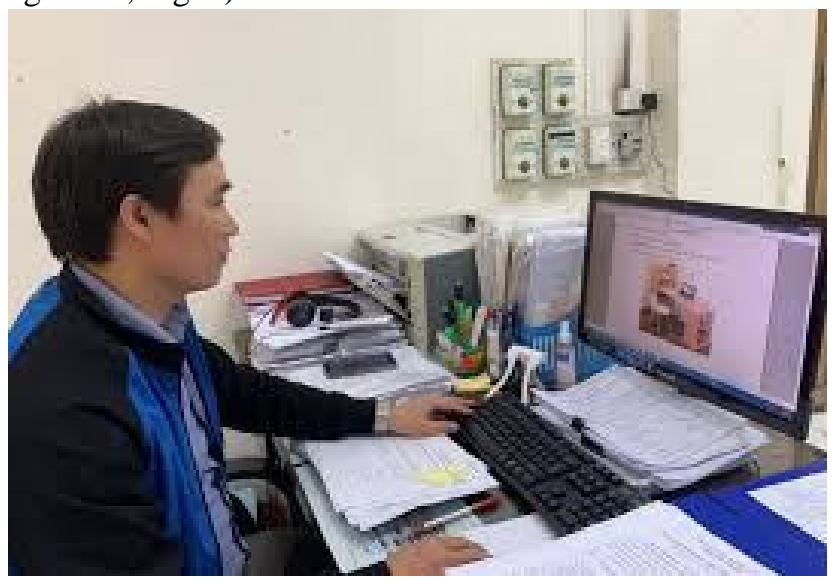

Fig. 1. Illustration of a teacher teaching online at work.

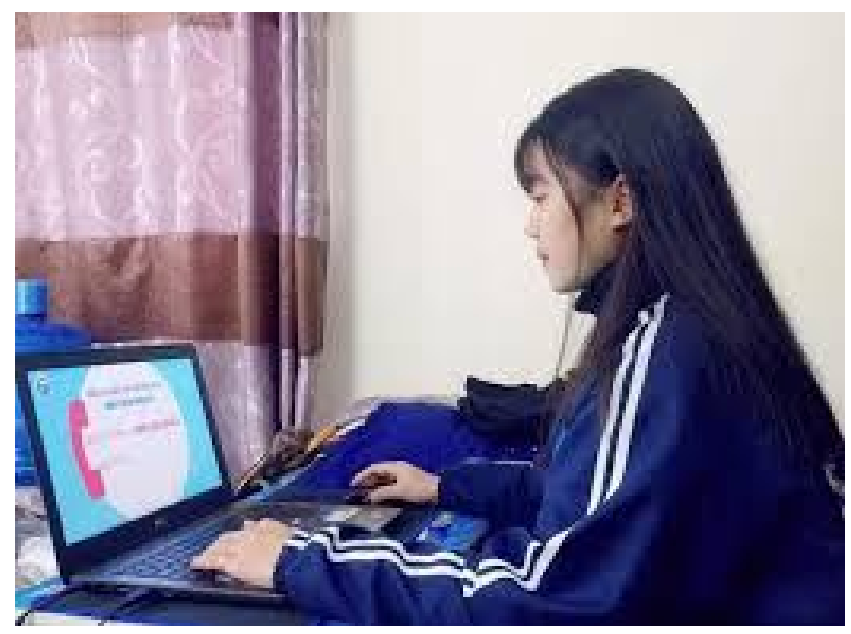

Fig.2. Illustration of a student learning online at home.

In response to this emergency epidemic, we defined a basic set of conditions. A solution that satisfies the conditions for online teaching in an emergency epidemic must ensure the following criteria:

1. The visual interface, easy-to-use: Ensuring that most teachers and students of all ages can learn how to use it quickly. A hard to use the software is not feasible.

2. Suitable for many different platforms and devices: Users can install easily and quickly on computers, laptops, smartphones, suitable for Windows, MAC, IOS, Android operating systems.

3. The software does not require special settings during the setup and registration process: Users only need to provide the minimum information to register. This issue ensures all teachers (who do not have much exposure to IT in many different industries and fields) or students among all school-age can use it.

4. Costs: With most schools in middle and low-income countries, the use cost is a critical issue. Moreover, in emergency pandemic situations, it is difficult to have significant expenses for online training systems.

5. The ability to feedback, assignments and tests.

6. Communication in the Classroom, in Table 3.

Table 3. Specific communication criteria in the Online Classroom.

\begin{tabular}{|l|l|}
\hline \multicolumn{1}{|c|}{ Teacher } & \multicolumn{1}{c|}{ Learner } \\
\hline - Observe the Classroom. & - Observe the lecture (Pictures, \\
- Lecture (Pictures and audio). & languages). \\
- Communicate with an & - Speak opinions (Active or \\
individual. & when invited). \\
- Demonstrate partial or full & - Communicate in the whole \\
screen to students for & class or the teacher. \\
observation. & - Communicate with the \\
- Can invite students to & teacher. \\
enter/leave the Classroom. & - Can share documents for the \\
- Possible to put Password for & teacher. \\
class. & - Can do the tests. \\
- Can take classes for class sizes. & - Can communicate with \\
- Can share documents for & individual teachers or other \\
students. & students. \\
& \\
\hline
\end{tabular}

\section{The E-LEARNing Support SOlutions}

Based on the defined criteria and purposes, we have surveyed and analyzed the online learning support software, specifically as follow:

Google Classroom [8], called Classroom, which is a limited free product of Google to support teaching and learning on an online platform. It has characteristics as follows:

- Accessibility: Users can access the Classroom from any platform or smart device via Google Chrome anytime, anywhere. Teachers and students can store and share files in a Classroom folder on Google Drive.

- Communication: Classroom makes communicating with students and parents easy. Teachers and students can send private comments on assignments and provide feedback on work. Besides, teachers can also communicate with parents through built-in tools such as individual emails.

- Collaboration: System offers some ways for students to collaborate. Teachers can facilitate online discussions by creating a group within the Classroom. Besides, students can collaborate on Google Docs application which has been shared by the teachers.

- Feedback: It providing meaningful feedback to students is a valuable part of all learning. Teachers can send feedback to each student.

- Data Analysis: In order to make teaching and learning meaningful, teachers could analyze data from assessments. Data from assessments can be exported into Excel. 
Although there are many advantages and it is a tool to create exercises, evaluate competencies as well as get feedback of learners very conveniently and effectively, a drawback of the solution is the support to communicate face to face. Meanwhile, it is the main task in organizing online teaching when offline classes cannot be held.

Skype Meeting [9] is a network-intensive program. It is one of the popular online tool helping with the communication of online training. Skype has many characteristics, as follows: Skype allows the people to work from everywhere, it has many helpful features including group video, learners can communicate with teachers or other students, and it helps the teachers communicate in group students from different places. Skype meeting is easier for the students and the teachers to reconnect. It also helps to exchange the data in the real-time so the presentations can reach multiple students in multiple locations; it can allow them for quicker deliberation, collaboration, and decision making. Although there are many advantages and is a tool to create video conferences easily. Skype Meeting have not tools to evaluate competencies as well as get feedback of learners. Moreover, it is free with the basic version, which has much limited, so if a user wants to use a full version, it is rather expensive and could is a financial challenge.

Zoom meeting [10] is Cloud-based Meeting Solutions, all-in-one number one leading communication solution, as named by Gartner in 2017. Zoom is the all-in-one solution for online collaboration. It allows both schools and businesses instant access to Video meetings, Webinars, Group chats, High Definition Screen Sharing ability, Vast training opportunities, Video and audio conferencing and other functions. Two outstanding advantages of Zoom is Mobility and Performance.

Zoom is set up with mobility and performance for all small and large online classrooms, whether there are only two people (teacher and one student) or up to five hundred people. Learners and teachers have direct access to this state of the art technology for the best in class audio and Video to keep students and teachers collaborating no matter. Zoom conference app offers the best quality video and audio and screen share, which work with almost all Video conferencing types of equipment. Unique, Zoom works across all mobile devices with ease. Although there are many advantages such as High Definition Screen Sharing ability, vast training opportunities, Video and audio conferencing very easily and quickly, Zoo Meeting is only free for 40 minutes per session with the account basic. So to remove the 40-minute time limit on free Basic accounts for schools affected by the Coronavirus, teachers with school email accounts had to submit a require to the Zoom.

Microsoft Team, similar to the Google Classroom or Zoom meeting, Microsoft Team is the product of Microsoft for Education [11], which is a cloud solution that allows organizing online classes, build collaborative classrooms, connect in learning communities, and connect with colleagues. Unique, Microsoft Teams is free for the entire schools. The schools need only verify are an accredited academic institution to get started. Microsoft Team has many advantages follow as:

- Connection everyone, anywhere.

- Connect with other teachers through professional learning communities.

- Bring teachers, school, students together to organize activities, club events.

- Students, teachers, and staff can seamlessly work together, create content, and share resources all from a single, easy-to-learn and simple to use platform.

- Collaboration: Co-author files and share resources with built-in Office 365 apps.

Although there are many advantages such as free with version basic, Connection everyone, anywhere, However, a huge drawback of Microsoft Team is the ability fast deployment system to organize an online classroom.

Unlike Zoom, Skype or Google classroom, Microsoft Team really need an administrator system who have certain knowledge about the network system to set up the system. It requests administrators create entire email account of learners, teacher as well as must assign classroom management rights to the teachers. Therefore, to deployment this Microsoft Team, schools should organize training courses for teachers. Based on the evaluation criteria we defined in Section 2, we summarize the advantages and disadvantages of each software/solution, as shown in Table 4.

Table 4. Evaluate solutions according to several criteria.

\begin{tabular}{|c|l|l|l|l|l|l|}
\hline Or. & \multicolumn{1}{|c|}{ Criteria } & $\begin{array}{c}\text { Zoom } \\
\text { Meeting }\end{array}$ & $\begin{array}{c}\text { Skype } \\
\text { Meeting }\end{array}$ & $\begin{array}{c}\text { Google } \\
\text { Classroom }\end{array}$ & $\begin{array}{c}\text { Microsoft } \\
\text { Team }\end{array}$ & $\begin{array}{c}\text { Our } \\
\text { Proposed }\end{array}$ \\
\hline 1 & Visual interface, easy use & Excellent & Excellent & Good & Good & Excellent \\
\hline 2 & Suitable for many different platforms and devices & Excellent & Excellent & Excellent & Excellent & Excellent \\
\hline 3 & No special requirements during the setup process & Excellent & Excellent & Good & Good & Good \\
\hline 4 & Classroom communication (Teachers and students) & Excellent & Good & No & Excellent & Excellent \\
\hline 5 & Feedback, Test, Evaluate & Good & Good & Excellent & Good & Good \\
\hline 6 & Deployment costs & Expensive & Expensive & Good & Good & Free \\
\hline
\end{tabular}




\section{OUR PROPOSAL SOLUTION}

Our proposed solution is built an Online Training Systems, based on the Bigbluebutton [17] video-conferencing open-source software, Ubuntu operating system and existing cloud server systems of the school (in Fig. 3). The Bigbluebutton is free, open-source software, this software has basic features for online training such as Chat, Webcams, Audio, Emojis, Breakout Room, Polling, Screen Sharing, Multi-user whiteboard. Basically, we changed 02 modules, including Login Module and User Interface Module. Finally, we installed it on a system of 3 cloud servers with the application configuration shown in Fig. 4.

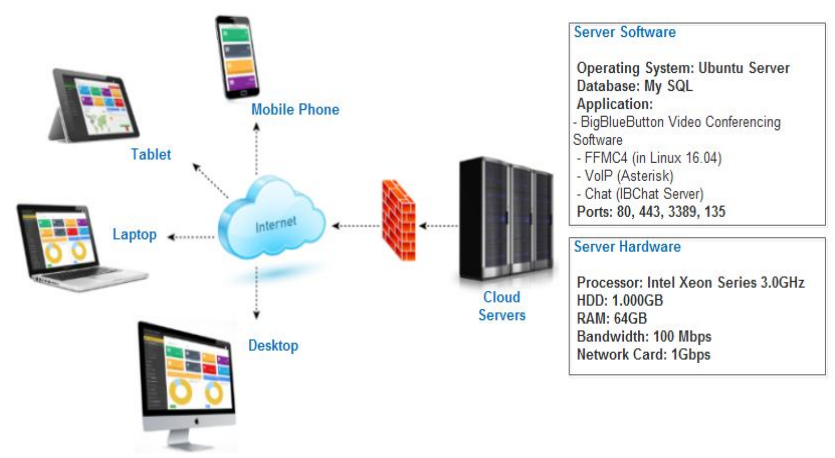

Fig. 3. Our proposed solution model.

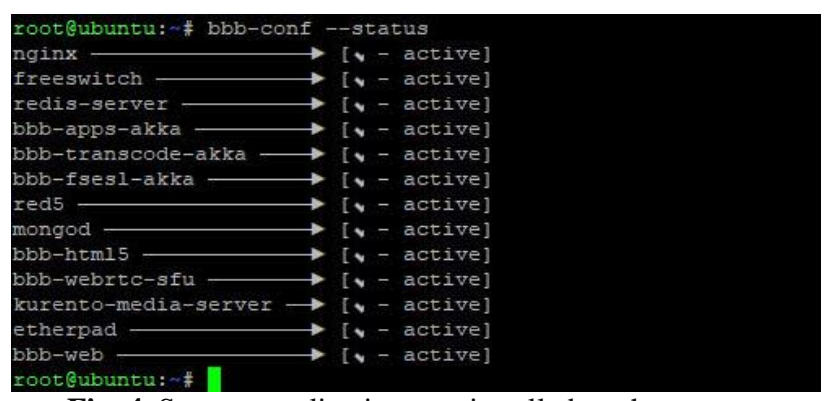

Fig. 4. Support applications are installed on the system.

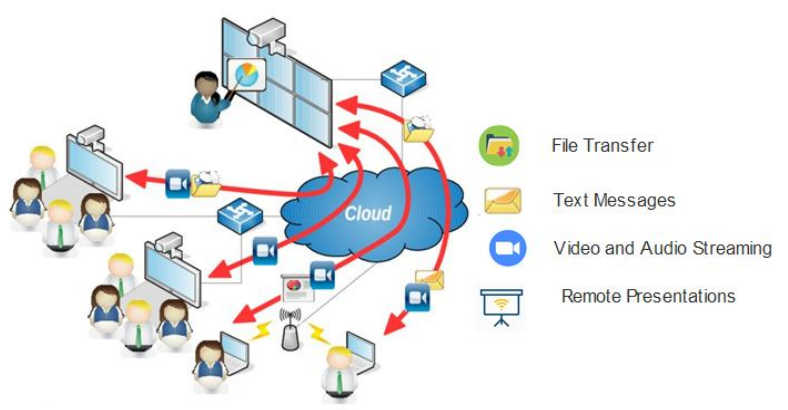

Fig. 5. Illustrate interaction in a classroom betweenteacher and students.

The system allows teachers and students to interact with each other via Video and Audio, Text Messages, Remote Presentations and File Tranfer as shown in Fig. 5. To make it simple for teachers and students, our system uses an administrator to create all accounts for teachers and students.
Teachers only need to log in the system and send the class code to students. Students only need to $\log$ in with the Username and Password, which was provided by the school to $\log$ in and participate in classes by laptops, smartphones or other mobile devices. With this solution, we fully proactively monitor the lessons and are not bound by the time and cost limits compared to the other solutions mentioned in Section 3.

\section{EXPERIMENTAL RESULTS AND DISCUSSION}

In this situation, UTEHY's Board of Directors had a quick meeting and allowed the teachers to actively seek solutions so long as they could organize teaching, and transfer knowledge to students. The most important thing is not to gather students to limit the spread of Coronavirus. As a result, teachers are proactively selecting software. The survey results of 1506 students and teachers participating in the course are listed in Fig. 6 - Fig. 13 and are summarized in Table 5.

In this work, we have set up an online training system based on the BigBlueButton open-source software. Our solution works on the Ubuntu open-source operating system and the existing cloud server system of UTEHY. Our solution can provide free online learning to all UTEHY students and teachers. In order to evaluate performance of the proposed solution, we surveyed on 1506 partners (students and teachers) of the school who participated in teaching/learning on our system and compared with 4 popular and professional online learning tools: Zoom Meeting, Microsoft Team, Google Classroom and Skype Meeting. Surveyed results are statistic and summary in Table 4.

Surveyed results show that each solution has advantages and disadvantages. If Microsoft Team and Google Classroom are announced as free support for the Education field; Skype and Zoom are free limited edition. Specifically, Zoom is free only for basic accounts limited to 40 minutes per connect session, while Skype limits the number of participants in a session to not more than 20, in while, about theory, our solution can support not limited the number of class and students. In contrast, if Microsoft Team and Google Classroom rather difficult to set up a class as well as in teaching processing, Zoom, Skype and our proposed are very simple for both teachers and learners to set up a classroom. Regarding the friendly and easy-to-use interface criteria, Zoom and our solution are selected highest, reach about $90 \%$, Fig. 6, but the Upgrade account of Zoom is quite expensive, about $\$ 15 /$ month/account while our solution is free. The survey results in Table 2 also show that Zoom Meeting is rated best since it reaches 4 out of 6 criteria at "Excellent" level. Meanwhile, our proposed solution reaches 3 out of 6 criteria at "Excellent" level. Only the Google Classroom achieves "Excellent" level at Criteria 5 about the Ability to feedback, test, evaluate. 


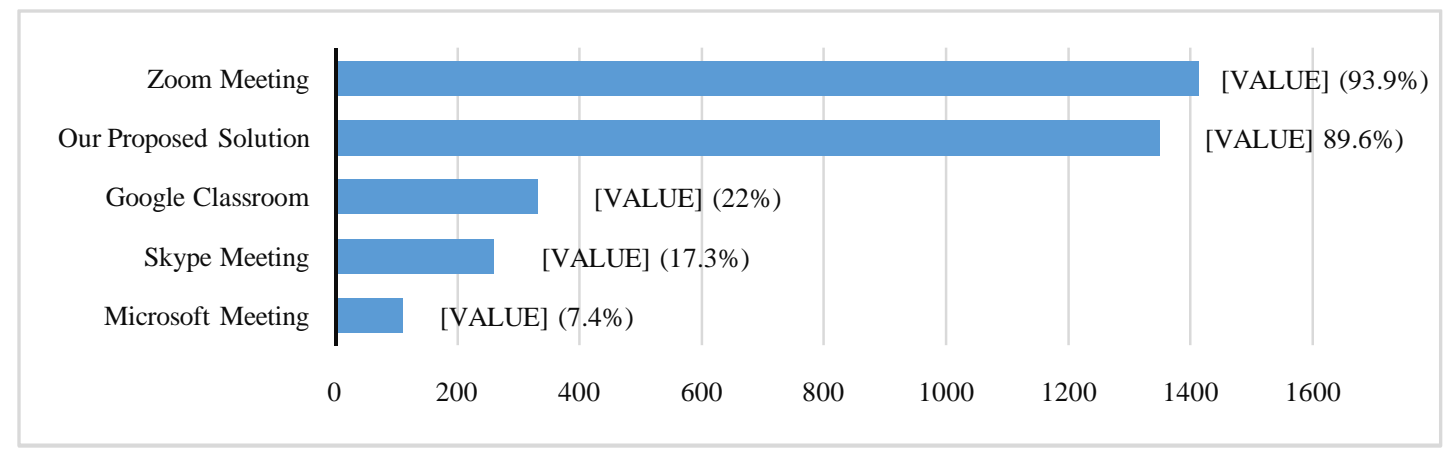

Fig. 6. Survey results based on Visual interface, easy to use criterion.

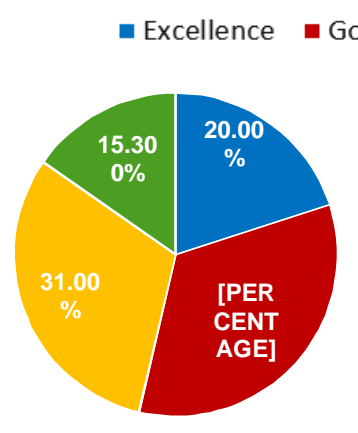

Fig. 7. Students feel excited criterion.

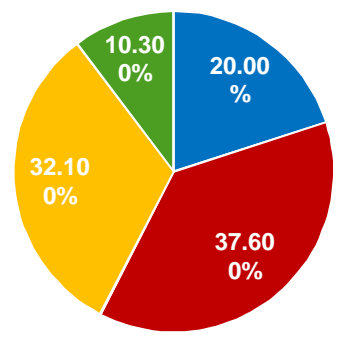

Fig. 9. Active in learning criterion.

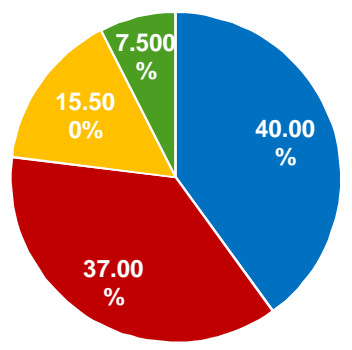

Fig. 11. Feel safe criterion.
Fig. 8. Ability to acquire knowledge criterion.

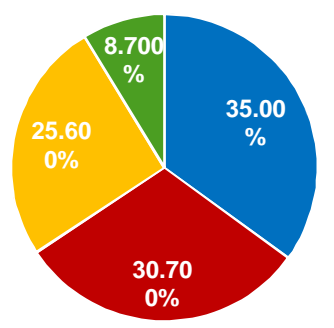

Fig. 10. Save time criterion.

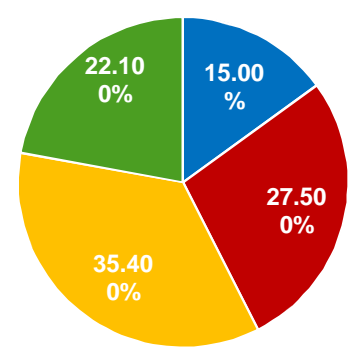

Fig. 12. Limited compared to Offline criterion.

While each online training solution has advantages and disadvantages, choosing which solution depends on economic

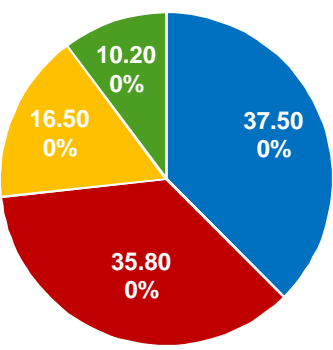

Fig. 13. Survey results based on Need to maintain after the disease criterion.

conditions, ability and capacity to operate technology as well as habits of users. However, in the context of circumstances such as the COVID-2019 disease outbreak quickly spreading worldwide, schools have invested in professional LMS systems, the deployment of distance learning for students is quite good. Unfortunately, the schools in general and universities in particular in middle and low-income countries are not equipped with such systems, so the application of effective technology solutions, low cost and can work well on a lot of device platforms is a significant challenge. It should be noted that UTEHY is a public university, under the Ministry of Education and Training in Vietnam and Vietnam is a country belonging to the group of middle and low-income countries. Most schools in Vietnam are not yet equipped with professional LMS systems. Based on these evaluations, at UTEHY, we have implemented our proposed solution to training online and Google Classroom to give out and evaluate assignments. 
Table 5. Surveying students after 1 month of studying online in COVID-19 pandemic.

\begin{tabular}{|c|l|r|r|r|r|}
\hline \multirow{2}{*}{ Order } & \multicolumn{2}{|c|}{ Criteria } & \multicolumn{4}{|c|}{ Evaluation Level } \\
\cline { 3 - 6 } & & Excellence & \multicolumn{1}{c|}{ Good } & Rather & \multicolumn{1}{c|}{ Limited } \\
\hline \multirow{2}{*}{1} & Visual interface, easy to use & \multicolumn{2}{|c|}{ Zoom: 93.9\%; Our proposed Solution: 89.6\%; Google } \\
& Classroom: 22\%; Skype: 17.3\%, Microsoft Meeting: 7.4\% \\
\hline 2 & Students feel excited & $20.0 \%$ & $33.7 \%$ & $31.0 \%$ & $15.3 \%$ \\
\hline 3 & Ability to acquire knowledge & $10.0 \%$ & $39.7 \%$ & $31.7 \%$ & $18.6 \%$ \\
\hline 4 & More active in learning & $20.0 \%$ & $37.6 \%$ & $32.1 \%$ & $10.3 \%$ \\
\hline 5 & Save time & $35.0 \%$ & $30.7 \%$ & $25.6 \%$ & $8.7 \%$ \\
\hline 6 & Feel safe & $40.0 \%$ & $37.0 \%$ & $15.5 \%$ & $7.5 \%$ \\
\hline 7 & Limited compared to Offline class & $15.0 \%$ & $27.5 \%$ & $35.4 \%$ & $22.1 \%$ \\
\hline 8 & Need to maintain after the disease & $37.5 \%$ & $35.8 \%$ & $16.5 \%$ & $10.2 \%$ \\
\hline
\end{tabular}

In recent time, many studies focus on optimizing solutions for e-learning, indicated in [13-15, 22]. However, as presented in the above sections, in emergencies due to the outbreak of pandemics (COVID-19 is an example), the schools do not have time and the limited investment source. Deploying Online training for a large number of students is a big challenge. A preliminary survey of the students after one-month eLearning to cope with the COVID-19 pandemic as in Fig. 6-13. Results show that over 85\% of teachers and students evaluate our proposed solution is excellent at the easy to use criteria. It is synonymous with students quickly get acquainted with this software. Over $90 \%$ of students evaluate criterion 4 as excellent; this means that students are more active in learning. Over $95 \%$ of students evaluate criterion 5 as excellent. It is synonymous with students feel it saves time. They do not spend more time to travel, and a vital point is over $90 \%$ of students feel safe in criteria 6 . Results show that teachers and students generally adapt quite quickly in new learning conditions to prevent COVID-19 pandemic; students are quite excited about the new learning conditions. The results when applied this integrated training solution at UTEHY show a general framework to deploy the online training for all schools of low and middle-income countries, which are still not yet investing in professional LMS systems, affected by the Coronavirus or other pandemics.

\section{CONCLUSION AND FURTHER RESEARCH}

While this research is being done, epidemics are still happening worldwide [21]. According to BBC [16], in Italy alone, the number of deaths from the Coronavirus increases 475 people per day and has exceeded 3,000 people. Scientists have not been able to predict when the COVID-19 pandemic will be controlled. Now there is not yet a vaccine to treat Coronavirus, and more and more countries have adopted the ban on large gatherings; this means students are not allowed to go to school. In this study, we have analyzed and compared the advantages and disadvantages of supportive solutions for organizing teaching and learning online in emergency epidemic situations. Experimental results at Hung Yen University of Technology and Education, a public university at Vietnam suggest a solution that combines our proposed solution and Google classroom to teaching, learning and in managing feedback and homework from students has initially gained effectiveness. We believe that our solution is perfectly suitable and can be implemented in emergencies for schools in countries affected by the epidemic, but does not have economic conditions to invest in professional LMS systems.In the next future, we will conduct research and propose solutions using MANET [25] and Cloud [26] network technology to issue warnings when a person has close contact with someone who is likely to be infected with the coronavirus.

\section{ACKNOWLEDGEMENT}

The authors sincerely thank Dr Nguyen Van Hau and Dr Dang Thi Huong Thao for their comments and suggestions for this research.

\section{REFERENCES}

1. COVID-19, https://www.who.int

2. Coronavirus, https://www.who.int/health-topics

3. Timeline of the 2019-20 Coronavirus Pandemic, https://en.wikipedia.org

4. Italy extends Coronavirus lockdown to the entire country, imposing restrictions on 60 million people, https://www.washingtonpost.com

5. Korea Corona Virus, https://www.theguardian.com, accessed March 06, 2020.

6. Vietnam Map and Satellite Image, https://geology.com, accessed March 06, 2020

7. Lan T. Phan et al. Importation and Human-to-Human Transmission of a Novel Coronavirus in Vietnam,New England Journal of Medicine, 382(9), pp. 1-2, 2020. DOI: 10.1056/NEJMc2001272

8. Google Classroom, https://classroom.google.com

9. Skype Meeting, https://www.skype.com

10. Zoom Meeting, https://zoom.us

11. Microsoft Team, https://microsoft.com

12. Hung Yen University, http://www.utehy.edu.vn

13. Ahmed Al Mulhem. Exploring the Key Factors in the Use of an E-Learning System Among Students at King Faisal University, Saudi Arabia,International Journal of Interactive Mobile Technologie, 14(30): pp. 19-37, 2020. Doi: 10.3991/ijim.v14i03.11576

14. Mohammed Ouadoud, Tarik Chafiq, Nouha Rida, Mohamed Yassin Chkouri. Generate a Meta-Model 
Content for Collaboration Space of Learning Management System Compatible with IMS-LD, International Journal of Interactive Mobile Technologie, 13(1): pp. 37-52, 2019.

15. Jelena N., Antonija B., Nikola M. User-Centred Design in Content Management System Development: The Case of Emasters, International Journal of Interactive Mobile Technologie, 13(8): pp. 43-59, 2019.

16. Italy Coronavirus deaths rise by record 475 in a day, https://bbc.com

17. BigBlueButton, http://bigbluebutton.org

18. N. Zheng et al. Predicting COVID-19 in China Using Hybrid AI Model, IEEE Transactions on Cybernetics, 50(7), pp. 2891-2904, 2020.

19. V. Marmarelis. Predictive modelling of Covid-19 data in the US: Adaptive phase-space approach, IEEE Open Journal of Engineering in Medicine and Biology, 2020.

20. M. Abdel-Basset, R. Mohamed, M. Elhoseny et al., A Hybrid COVID-19 Detection Model Using an Improved Marine Predators Algorithm and a Ranking-Based Diversity Reduction Strategy, IEEE Access, Vol. 8, pp. 79521-79540, 2020.

21. F. Rustam et al., COVID-19 Future Forecasting Using Supervised Machine Learning Models, IEEE Access, 8: pp. 101489-101499, 2020.

22. J. Romero-Rodríguez, I. Aznar-Díaz, F. Hinojo-Lucena and G. Gómez-García. Mobile Learning in Higher Education: Structural Equation Model for Good Teaching Practices,IEEE Access, Vol. 8, pp. 91761-91769, 2020.

23. Ha, K., A Lesson Learned from the Outbreak of COVID-19 in Korea. Indian J Microbiol 60, pp.396-397, 2020.

24. Privitera, D., Angaroni, L., Capsoni, N. et al., Flowchart for non-invasive ventilation support in COVID-19 patients from a northern Italy Emergency Department,Intern Emerg Med 15, pp. 767-771, 2020.

25. Vu Khanh Quy, Pham Minh Chuan, Vi Hoai Nam, Dao Manh Linh. A Review on Security-aware Routing Protocols for Mobile Ad hoc Network, International Journal of Advanced Trends in Computer Science and Engineering, Vol. 9, No. 3, pp. 3655 - 3661, 2020.

26. Olga I. Vaganovaet al., Comparative analysis of Cloud Technologies, International Journal of Advanced Trends in Computer Science and Engineering, Vol. 9, No. 3, pp. 2563 - 2566, 2020. 